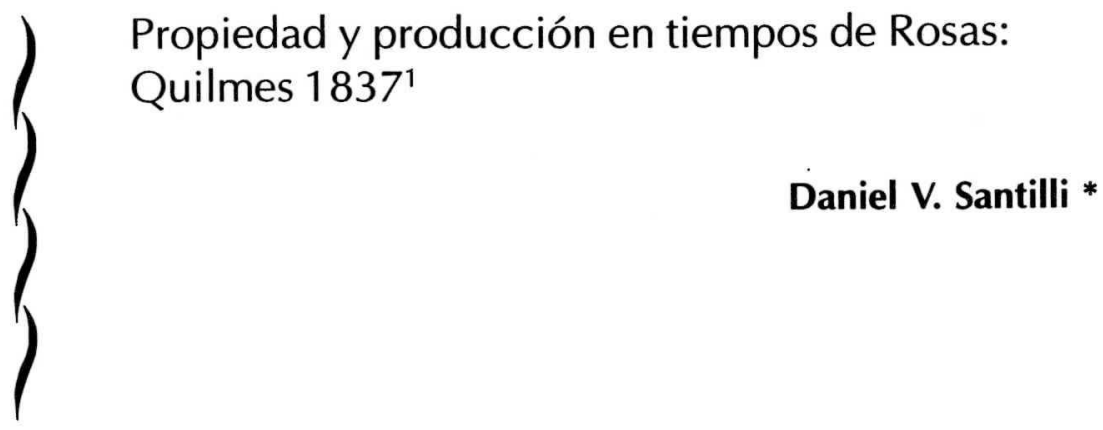

\title{
Introducción
}

1837 es tal vez el último año de un florecimiento económico que comienza con el fin, en 1829, de los graves conflictos políticos en que desembocó la feliz experiencia y el fin de la gran sequía en 1832 . El ordenamiento de las cuentas estatales que se produce durante el primer mandato de Rosas y es continuado por sus sucesores produce una tranquilidad fiscal que promueve los negocios. La traumática sequía de 1829 que diezmó el ganado al punto que hubo regiones de la provincia que, diez años después, no se habían recuperado ${ }^{2}$, llegó a su fin en 1832 y dejó el camino expedito para la reproducción del stock ganadero y la recuperación de la agricultura. La campaña al desierto de 1833 aseguró las fronteras de las incursiones de los indios, a la vez que

\footnotetext{
' El presente trabajo complementa nuestro anterior sobre la población de Quilmes, donde se habían analizado aspectos demográficos, sobre todo la expansión de la cantidad de habitantes. Pretendemos ahora; incorporarle el estudio sobre los aspectos económicos de esa expansión, es decir el marco productivo sobre el cual implantaba esa nueva población. Santilli (2000). Una versión previa fue presentada en las Segundas Jornadas de Historia Económica de la Asociación Uruguaya de Historia Económica, llevadas a cabo en Montevideo en julio de 1999. El autor agradece los comentarios vertidos en esa oportunidad por la comentarista Lucía Sala de Touron, como así también las observaciones de Jorge Gelman y Raúl Fradkin, y las del evaluador anónimo convocado en oportunidad de la presentación del artículo en la Revista. Las opiniones vertidas, por supuesto, corren por cuenta del autor.
}

${ }^{2}$ GARAVAGLIA (1998) 
amplió la zona de implantación de la economía blanca, dejando a los antiguos dueños -precisamente los indios- sin su tierra, aunque se les reconocieron derechos a partir del conocido "negocio pacífico". Sobre esa nueva superficie se produjo la última concesión de tierras en enfiteusis otorgándose impresionantes extensiones a un puñado de hombres ${ }^{3}$. Por último, aunque no menos importante, la ley de aduanas de 1835, tal vez arrancada al rosismo por las inquietudes del interior acerca del librecambio y por los labradores ${ }^{4}$ de Buenos Aires que presionaban para mantener y ampliar la agricultura, amparaba precisamente esa actividad de la importación de harinas. De ese modo, la actividad pretendía abastecer el mercado citadino y apuntar hacia una expansión al exterior que se vislumbraba ${ }^{5}$.

Pero esta bonanza se cortó en 1838. Los acontecimientos políticos hicieron temblar el andamiaje de esta economía. A la guerra con la Confederación Peruano-Boliviana, que tal vez más que una amenaza real era un síntoma, le sigue el conflicto con Francia que determinó el bloqueo al puerto de Buenos Aires, hecho que indudablemente perjudicó a los intereses de los ganaderos. Pero eso fue sólo el comienzo de lo que serían los últimos meses del año 1839, con el levantamiento de los Libres del Sur y la invasión de Lavalle. Estos acontecimientos, de los cuales el rosismo como sistema político pareció salir fortalecido, determinaron que la economía ya no fuera la misma durante la década de $1840^{6}$.

Por eso, 1837 nos parece un buen año para observar en un escenario privilegiado hasta qué punto las modificaciones introducidas por la doble expansión, la ganadera y la de la frontera ${ }^{7}$, se hacían o no sentir en las zonas más cercanas a la ciudad. A tal efecto, estudiaremos una pista acerca de la estructura de la propiedad en el partido de Quilmes, así como la de la tenencia de ganado. Además, reconstruiremos los registros para establecer las unidades de producción de cada propietario. De tal modo, estudiaremos la utilización de mano de obra de esas unidades.

El objetivo será tratar de probar nuestra hipótesis. Para nosotros, la expansión ganadera sobre tierras nuevas dejó a las zonas cercanas en inmejorables condiciones para lograr un desarrollo diferenciado de aquella, a partir del abastecimiento a la ciudad de cereales, hortalizas y frutales, producción ahora encarada con el mercado como primer objetivo. El abandono del autoconsumo como fundamento del cultivo de la tierra y la cría de algún

${ }^{3}$ INFESTA (1993)

${ }^{4}$ PEREYRA (1964)

${ }^{5}$ BURGIN (1975)

${ }^{6}$ HALPERÍN DONGHI (1972)

${ }^{7}$ HALPERÍN DONGHI (1963), (1975). 
ganado, cuyas sobras se vendían luego en el mercado, parece ser el principal cambio logrado en el período en las cercanías. Otro aprovechamiento de esa cercanía, sobre todo en la zona sur, era la implantación de los saladeros y el surgimiento de un comercio ligado al transporte del ganado y los cueros desde las zonas de producción. Por último, la cría de la oveja en el partido de Quilmes apareció como una novedad adelantándose en el tiempo a la fiebre del lanar de la segunda mitad del siglo, que ya había sido mencionada por Garavaglia y Gelman en sendos estudios ${ }^{8}$.

Además, veremos que la idea difundida sobre la preponderancia de la ganadería vacuna, la gran estancia y el latifundio en época de Rosas, no fue en este caso tan absoluta, tal como se está viendo para otros partidos de la campaña ${ }^{9}$, ya que al lado del gran establecimiento existía también la pequeña propiedad y el productor en escala reducida.

Veamos las particularidades del partido. Quilmes se extendía, en esa época, al sur de la ciudad desde el Riachuelo hasta las inmediaciones de la actual ciudad de La Plata y, hacia fines de la década de 1830, estaba dividido en cuarteles numerados desde el Riachuelo hacia el sur, según puede observarse en el Anexo I, y se correspondía con las siguientes localidades actuales:

Cuartel 1: Avellaneda hasta Crucecita, Dock Sud, Gerli, Puente Alsina. Cuartel 2: Lanús, Lomas de Zamora, Santa Catalina, Monte Chingolo. Cuartel 3: Sarandí, Villa Dominico, Wilde, Bernal Oeste, San Francisco Solano.

Cuartel 4: Quilmes, Quilmes Oeste.

Cuartel 5: Berazategui, Florencio Varela.

Cuartel 6: Villa Elisa hasta el Arroyo del Gato.

El pueblo de Quilmes y sus chacras aledañas ocupaban el cuartel 4, cuya delineación y asignación de tierras se había realizado en $1818^{10}$ sobre las tierras de la antigua reducción de los indios Quilmes, que funcionó desde 1666 hasta que fue liquidada en $1812^{11}$. En las cercanías del Puente del Restaurador, hoy Puente Pueyrredón, nos encontramos con una serie de comercios ligados al tránsito sobre dicho puente que estaban prefigurando lo que a partir de 1852 sería la cabecera del partido de Barracas al Sur (actual Avellaneda) ${ }^{12}$. En el centro de la actual Lomas de Zamora, se había realizado una subdivisión

${ }^{8}$ GELMAN (1996b) y GARAVAGLIA (2000)

${ }^{9}$ GELMAN (1996ª); GELMAN (1996b); BROWN (1979); INFESTA (1994); MASCIOLI (1999)

${ }^{10}$ Ver el "Plano de los terrenos de los Quilmes de $1 / 2$ legua de frente y $11 / 2$ de fondo dividido en parte de solares para pueblo y suertes de chacras para labranza mandado levantar por orden del Sr. Gobernador Intendente Don Manuel Oliden al Comisionado Juez Comisario de Policia Don Felipe Robles y Agrimensor de Proyecto Francisco Mesura en marzo de 1818" AGN I-223.

"Sobre la reducción, ver PALERMO y BOIXADOS (1991) y OTAMENDI (1968)

${ }^{12}$ TORASSA (1940) 
en chacras en 1821 sobre una fracción de tierras del Estado, conocida como la Estancia de Zamora, cuyos principales impulsores y beneficiarios habían sido los Grigera ${ }^{13}$, hijos de Tomás, el "alcalde de las quintas" de la asonada del 5 y 6 de abril de $1811^{14}$. Se trataba de un conglomerado de chacras instaladas a la vera del camino Real hacia San Vicente. En el resto del partido, no había núcleos poblacionales de magnitud, sólo alguna posta o pulpería solitaria a la vera de rutas que era cada vez más importantes para traer ganado desde más al sur $^{15}$, para atender al abasto porteño y a los saladeros que entre prohibiciones y autorizaciones funcionaban más o menos clandestinamente en la costa del Riachuelo y de los arroyos de Sarandí y Santo Domingo, hoy partidos de Lanús y Avellaneda ${ }^{16}$. Recordemos que en esta zona, más precisamente en Monte Chingolo, funcionó el saladero Las Igueritas (sic), propiedad de la sociedad de Rosas, Terrero y Dorrego, desde 1815 y por unos pocos años ${ }^{17}$. En las inmediaciones de la laguna Santa Catalina, se había asentado en 1825 una colonia escocesa, gestionada por los hermanos Parish-Robertson, que funcionó como tal hasta $1829^{18}$. Para la época que nos ocupa, algunos de los inmigrantes que la formaron permanecían en la zona. Había también una zona intermedia entre Avellaneda, Lanús y Lomas, por un lado y Quilmes, Berazategui y Florencio Varela hacia el sur, que coincidía más o menos con la cuenca de los arroyos Las Piedras, San Francisco y Santo Domingo, hoy entubado, que en aquel tiempo era un bañado en buena parte de su recorrido. Esta cuenca se convirtió con posterioridad en el límite de los partidos de Barracas al Sur y Quilmes en $1852^{19}$.

Luego de esta pequeña introducción, pasemos a describir la documentación base de nuestro trabajo.

\section{La fuente}

Como es ya sabido, la producción agroganadera estaba gravada, durante la colonia, por el diezmo, tributo que percibía la iglesia y que significaba el $10 \%$ de la misma. Dicho gravamen fue anulado durante los años de la feliz experiencia para dar lugar a la aparición de la contribución directa, imposición ya no religiosa que era percibida por el Estado. Es decir, a diferencia

\footnotetext{
${ }^{13}$ DE PAULA y GUTIÉRREZ (1969: 89).

${ }^{14}$ CUTOLO (1971: 458).

${ }^{15}$ Se les asignaba el nombre de camino de las tropas, y dos de ellos son las actuales Av. Frías en Lomas de Zamora y la Av. Donato Álvarez en San Francisco Solano.

${ }^{16}$ TORASSA (1940: 55ss) y DE PAULA, GUTIÉRREZ VIÑUALES (1974: 90).

${ }^{17}$ TORASSA (1940: 54).

${ }^{18}$ DE PAULA y GUTIERREZ, (1974: 119ss).

${ }^{19}$ DE PAULA, GUTIERREZ y VIÑUALES, (1974: 94).
} 
del diezmo, que engrosaba las arcas de la iglesia, la contribución directa formaba parte de los ingresos del estado provincial. Por otro lado, si el antiguo canon alcanzaba a la producción tanto agrícola como ganadera, el nuevo impuesto alcanzaba al patrimonio en tierras, instalaciones y ganados. También reemplazó a otros gravámenes comerciales, como la alcabala, gravando al capital comercial. El mínimo imponible se fijó en \$2000 para los casados y en $\$ 1000$ para los solteros ${ }^{20}$. Luego, en 1839 fue modificado de manera tal que desapareció ese mínimo y se incluyó a los enfiteutas en la base imponible ${ }^{21}$. Según diversos autores ${ }^{22}$, este nuevo recurso debía, con el tiempo, disminuir la excesiva dependencia que el fisco porteño tenía con respecto a los ingresos de su aduana. Sin embargo, nunca pudo lograr ese objetivo. En 1830 representaba el $10 \%$ de todos los ingresos del estado bonaerense, estabilizándose en alrededor del $12 \%$ hasta mediados de la década y decreciendo al $3 \%$ entre 1840 y 1850 , con la sola excepción de 1846 , que trepó al $11 \%$, no porque se incrementara su valor absoluto, sino porque los ingresos de la aduana cayeron a raíz del bloqueo del puerto ${ }^{23}$. Y para muestra basta la infinidad de acciones ejecutadas a medias contra los morosos por los diversos funcionarios como los jueces de paz, los jefes de policía, los integrantes de la Colecturía General o los contratistas privados que se encargaron de su cobro entre 1824 y $1836^{24}$. Además, la ley original permitía que cada contribuyente hiciese su declaración jurada de bienes y sobre ella calcular el impuesto a pagar, hecho que, según las discusiones en la Sala de Representantes, no era del agrado de los diputados por la campaña, sobre todo Anchorena ${ }^{25}$. De tal oposición se hizo eco, tiempo más tarde, el propio Rosas, reconociendo que "no había nada más cruel e inhumano que obligar a una persona a que diera cuenta de sus riquezas privadas $^{\prime 26}$. Es, por tanto, casi una certeza suponer que la evasión y la declaración falsa eran una regla en la campaña.

Esta aclaración bien vale porque el presente trabajo se realizó en base a un censo destinado a la percepción de dicho impuesto. En efecto, el "Padrón de haciendas, suertes de Estancias y Chacras perteneciente al Partido de Quilmes y a los capitalistas que han pagado la Contribución Directa hasta el año pasado de $1836^{\prime \prime 27}$, fechado el 22 de diciembre de 1837, debe adolecer de las fallas mencionadas como la evasión y la falsedad. Pero además sospechamos que

\footnotetext{
${ }^{20}$ Sobre contribución directa ver ESTÉVEZ (1960) y NICOLAU (1988).

${ }^{21}$ BURGIN (1975: 249).

22 Por ejemplo, el ya citado BURGIN (1975); FERNS (1984: 115), y NICOLAU, (1988)

${ }^{27}$ BURGIN (1975: 81, 223 y 254).

24 ESTÉVEZ (1960).

${ }^{25}$ NICOLAU (1988)

${ }^{26}$ Mensajes del $1^{\circ}$ de enero y 27 de diciembre de 1827, citado por BURGIN (1975: 249).

27 AGN X-25-4-6
} 
muchos titulares de tierra y ganado del partido estaban inscriptos como contribuyentes en otra jurisdicción. Tal debe ser el caso de Manuel Obligado, hijo del gran comerciante colonial Don Antonio Obligado, que estaba radicado en la ciudad y era propietario de una parcela en Quilmes, en tierras de la actual localidad de San Francisco Solano ${ }^{28}$, y titular de otra en la zona sur del Partido, según el padrón de habitantes de $1838^{29}$. A la inversa, se observa el caso de Felipe Avellaneda, propietario en Quilmes de una suerte de 400 varas de frente por 6000 de fondo, y que también poseía una parcela en San Vicente, mencionada en esta fuente.

En el documento aludido constan, en varios folios, los nombres de 154 personas, algunos de ellos repetidos, con la indicación de la cantidad de tierra (medida en varas de frente y fondo), el tipo de establecimiento (chacra o estancia) y de ganado por los que han pagado el impuesto antedicho. Los nombres repetidos (11 en total) están indicando un mismo titular para dos parcelas diferentes. O sea que las 154 personas eran en realidad parcelas diferenciadas. Según el censo de 1838, había en Quilmes 648 unidades censales que, siguiendo la costumbre ya establecida en el análisis de este tipo de fuentes ${ }^{30}$, son consideradas unidades de producción, en su mayoría familiares. Obsérvese que pocas de estas UC pagaban un impuesto que gravaba el patrimonio, no la producción, ya que alcanzaba a la tierra y a las cabezas de ganado vacuno, ovino y caballar. Se podría suponer que la diferencia correspondía a arrendatarios instalados en estas mismas propiedades alcanzadas por el gravamen. Pero, salvo unas pocas, como vamos a ver, no eran lo suficientemente grandes para albergar tanta cantidad de gente. Para que existan arrendatarios tiene que haber arrendadores, es decir propietarios de tierra que la dan en arrendamiento, y que probablemente no vivan en la misma. Buscamos entonces propietarios absentistas que hubieran declarado su tierra en Quilmes. Verificamos la existencia de 26 casos de contribuyentes que no habitaban en el partido según los censos de 1836 y de 1838. De ellos, 19 eran propietarios de tierras. Pero, si se trataba de arrendadores, lo eran en pequeña escala ya que entre todos sumaban sólo 2177 Has. La mayor de esas parcelas llegaba a las 941 Has., a nombre de Encarnación Verón. Quedaban luego 18 propietarios con una extensión promedio de $68 \mathrm{Has}$. cada uno, lo que los hace irrelevantes como terratenientes arrendadores. La deducción que hacemos en consecuencia es que si había arrendatarios, estos alquilaban tierra de propietarios que no vivían en Quilmes y declaraban la propiedad de esta tierra en otra jurisdicción. La actividad de estos propietarios absentistas es imposible establecerla a partir de

${ }^{28}$ GULLOTTA (1994)

${ }^{29}$ AGN X-25-6-2

${ }^{30}$ GARAVAGLIA (1993b) 
esta fuente, ya que en ella no figuran.

No aparece ningún contribuyente por granos $u$ otra producción agrícola que pudiera tener almacenada, o que haya producido, aunque sí sabemos que los agricultores pagaban una tasa diferencial por la tierra si eran propietarios $^{31}$. Tampoco sabemos cuánto pagaba cada uno por lo que poseía, dato que nos serviría para trabajar con precios y para entender cómo funcionaban los mínimos imponibles que mencionábamos más arriba, ya que en el padrón figuran propiedades muy chicas, desde 50 por 250 varas, que equivale a 0.9 Has. En cuatro casos, todos ellos deudores del impuesto, aparece el monto adeudado. La mencionada Verón, propietaria de 941 Has., 3000 ovejas, 300 vacas y 200 caballos, debía $\$ 84$. Benito Troncoso, un apellido con tradición en la zona, era deudor por $\$ 70$ desde 1830 a 1836 por una parcela de 42 Has., más 600 ovejas. Antonina Avellaneda también adeudaba desde $1830 \$ 56$ por un terreno de 32 Has. Por último, don Silverio De la O no tenía tierras y no había pagado $\$ 20$ por 800 ovejas, 100 vacas y 75 caballos. No aparecen gravados los lotes de la subdivisión hecha en el pueblo, que eran de 50 por 50 varas, suponemos que porque no alcanzaban el límite a que hemos hecho referencia. En cuanto al ganado, el mínimo registrado era de 15 vacas, 200 ovejas o 15 caballos. Como se ve, seguramente eran muy pocos los que escapaban a este impuesto. Por lo tanto, el universo con el que contamos es lo suficientemente amplio para sacar conclusiones válidas al respecto, con las salvedades que ya mencionamos.

\section{Tamaño y tipo de las parcelas}

La cantidad de tierra contabilizada era de 26320 Has. que equivale al $37 \%$ de la superficie actual de los partidos que, aproximadamente, ocupaba Quilmes en 1838. Si vemos los planos catastrales de la zona más cercana a Buenos Aires confeccionados hacia $1820^{32}$, observamos que las tierras estaban ocupadas en su totalidad, por lo menos hasta más al sur del límite actual de Florencio Varela y Berazategui con Lomas de Zamora y Quilmes. Es evidente el subregistro, pero ello no invalida las conclusiones a las que arribaremos.

Ahora bien, ¿cuál es la escala de tamaños adecuada para analizar la estructura de tenencia de la tierra para esa época? En la fuente, las parcelas están separadas en suertes de estancias y de chacras. Las suertes de estancia debían tener 3000 varas de frente por 9000 (1 1/2 legua) de fondo, y las chacras de 350 a 500 varas de frente por 6000 de fondo $^{33}$. Pero ésta es la teoría, ya que

\footnotetext{
${ }^{31}$ BURGIN, (1975: 79).

${ }^{32}$ Por ejemplo DE PAULA y GUTIÉRREZ (1969: 88).

${ }^{33}$ AZCUY AMEGHINO (1995: 16 nota 1).
} 
nos encontramos con unidades consideradas estancias cuyas medidas eran bastante menores; $800 \times 3000$ varas, $2100 \times 4500,400 \times 9000$, etc. $Y$ entre las chacras, nos encontramos con parcelas declaradas como de 2, 31/2 y hasta 10 suertes. No pudiendo utilizar una frecuencia de tamaño basada en fuentes de la época, haremos uso de la que construyó Azcuy Ameghino ${ }^{34}$ para analizar el censo de hacendados de toda la campaña de 1789. Debemos hacer algunas consideraciones al respecto. El autor analizó un censo de propietarios anterior en 50 años al que aquí estudiamos, con lo que queremos hacer notar que las condiciones de explotación seguramente variaron. Además, tomó tres zonas más alejadas de la ciudad que la que estamos considerando, Magdalena, Pilar y Areco. Es probable que la incidencia de la ganadería sea mayor en estas zonas que en Quilmes y que la cercanía al principal mercado consumidor y exportador influya no sólo en la valorización de las tierras, sino también en las formas de explotación de las mismas.

Veamos en el cuadro 1 cómo se repartían esas 26320 Has. entre los 125 propietarios de tierra incluidos en los 154 contribuyentes, ya que figuran 29 casos que sólo contaban con ganado. No debemos olvidar que, seguramente, los propietarios más chicos están subregistrados, ya que tal vez muchos no llegaban al monto de $\$ 1000$ para los solteros y $\$ 2000$ para los casados. Sin embargo, en este cuadro puede observarse la difusión de la pequeña propiedad, dado que el $80 \%$ de las unidades eran menores a 200 Has. Claro está que sólo ocupaban el $18 \%$ de la tierra registrada. Por otro lado, sólo 3 parcelas superaban las 1000 Has. Y de acuerdo con los criterios de la época, sólo 2 de ellas podrían considerarse suertes de estancia. Si consideramos a las unidades de más de 200 hasta 1000 Has. como medianas, nos encontramos con que la mayor parte de la tierra estaba en ese escalón, aunque sólo el $18 \%$ de los propietarios accedía a ella. Si cruzamos este análisis con el tipo de explotación, (cuadro 2) con que el escriba ha catalogado a cada parcela, veremos que, como era de suponer las parcelas más chicas eran las denominadas chacras; 65 de ellas eran menores a 50 has., mientras que las estancias contaban con tamaños más diversificados, predominando los intermedios.

¿De qué nos están hablando estos cuadros? De un grado de concentración de la tierra que parece importante: sólo el $1.6 \%$ de los propietarios tenían el $36 \%$ de la tierra. Cincuenta años antes, en zonas más alejadas, el $2 \%$ de los propietarios poseía el $48 \%$ de la tierra ${ }^{35}$. En 1825 en San Nicolás, el $4.2 \%$ apenas si sobrepasaba el $19 \%$ de la tierra ${ }^{36}$. Quilmes parece ubicarse en un término medio entre estos dos extremos.

\footnotetext{
${ }^{34}$ AZCUY AMEGHINO (1995: 71ss).

${ }^{35}$ AZCUY AMEGHINO (1995: 85) Cuadro 8.

${ }^{36}$ CANEDO (2000: 211).
} 
Pero para completar el análisis, debemos tener en cuenta el tamaño de esas parcelas; ese $1.6 \%$ de propietarios se refería a dos parcelas que sumaban 9413 Has., que en realidad eran de una sola persona, Faustino Ximenez, en el cuartel 6. Por debajo, sólo encontramos una parcela que supera las 1000 Has. En cambio, la información de cincuenta años antes que manejamos nos muestra que ese $2 \%$ estaba compuesto por parcelas de más de 5000 Has. y otro $24 \%$ de la tierra estaba repartido en predios de más de 1000 Has. Para San Nicolás, el tamaño de ese $4 \%$ era de más de 2000 Has. y si tenemos en cuenta el rango de las 1000 Has. incorporamos un $22 \%$ de tierra y otro $8 \%$ de propietarios. También en este criterio, Quilmes se ubica en una zona intermedia.

Pero la reflexión a que nos lleva el estudio de la concentración de la propiedad de la tierra es a la verificación de la existencia o no de latifundios. Véase que decimos latifundios en plural, porque si bien no se puede negar que la propiedad de Ximenez era un latifundio, una golondrina no hace verano, y máxime cuando ese señor no es el dueño de toda la tierra disponible. Quedaba un $65 \%$ para el resto de los propietarios.

La segunda parte de esta reflexión nos lleva a considerar qué era un latifundio para la época. Según la ley de enfiteusis, èl mínimo a otorgar bajo ese sistema era la suerte de estancia, 2000 Has aproximadamente, y el máximo 12 leguas cuadradas, $32400 \mathrm{Has}^{37}$. Y, según otros testimonios, una suerte de estancia sólo producía 90 cueros al año a principios de siglo ${ }^{38}$. Pero estamos en 1837; un testimonio de época nos dice que en una legua cuadrada (2700 Has) vivían 1000 vacas, que podrían producir por procreo unos 200 cueros al año. Como vemos, no cambió mucho la situación con respecto a principios de siglo. Es decir, creemos que una suerte de estancia bajo ningún punto de vista puede ser considerado un latifundio porque no producía aún bienes suficientes para que su valor haga que el dueño pueda considerarse terrateniente.

Pero para completar este análisis, habría que tener en cuenta la calidad de las tierras de que nos ocupamos. Hoy día puede verse haciendo el camino del acceso sudeste a esta capital, donde se encuentra la planta de Cinturón Ecológico, que precisamente se hace relleno para evitar las inundaciones. En las cercanías de Punta Lara, muy cerca de Ensenada, la costa del río es pantanosa y, en general, toda la costa luego de la barranca es anegadiza. Asimismo, la cañada de Gaete, hoy arroyo Las Piedras-Santo Domingo, era un bañado, solucionado hace más de 30 años con el entubamiento del arroyo a la altura del Parque Dominico. A la inversa, la zona céntrica de Lomas de Zamora

${ }^{37}$ Citado por INFESTA (1993: 119).

${ }^{38}$ MAYO (1995: 37). 
habría sido privilegiada por su altura para la agricultura ${ }^{39}$. Es por eso que creemos conveniente confeccionar los cuadros anteriores diferenciando los cuarteles (ver cuadro 3 y 4), dato que no consta en el padrón que estamos utilizando como fuente, pero que hemos extraído de los padrones de habitantes de 1836 y $1838^{40}$.

Aquí podemos apreciar la concentración de las pequeñas parcelas en los cuarteles más poblados, el 2 y el 4, es decir Lomas de Zamora y Quilmes, que eran también los que contaban con mayor cantidad de unidades denominadas chacras. Otra observación relativa al cuartel 1 es que estaba formado por unidades chicas y para ser coherente, ninguna del tipo estancia. Se trataría de comercios o establecimientos que aprovechaban la costa del Riachuelo para realizar su cometido, por ejemplo, los saladeros, según nos lo indican los historiadores regionales ${ }^{41}$. Encontramos también una zona intermedia entre estos cuarteles, el 3, que tenía unidades más grandes. Por último, tenemos los cuarteles más alejados, que tenían precisamente las parcelas más grandes y mayoría del tipo estancia. En consecuencia, tenemos pequeñas parcelas cercanas a la ciudad y mayores en las zonas más alejadas. Obviamente, el tamaño y la denominación de la parcela están relacionados con la actividad; las más chicas estarían dedicadas a la agricultura y las más grandes a la ganadería. Esto coincide también con la cercanía al gran mercado que es Buenos Aires, aunque esta no es una obviedad porque el avance de la frontera en la costa del Uruguay entrerriano, a partir de Concepción, se produjo con los labradores que abastecían un mercado cada vez más alejado de esa ciudad ${ }^{42}$.

Otra pregunta que surge es ¿cuánta gente vivía en estas parcelas? Para tratar de responder, construimos el cuadro $5^{43}$. Como podemos observar, la cantidad de habitantes más generalizada rondaba los 10 componentes por unidad censal, tanto en las más pequeñas como en las medianas. Con estos datos, hemos obtenido los siguientes promedios (ver cuadros 6 y 7$)^{44}$. Según puede inferirse, las diferencias en parcelas de hasta 1000 Has. no son muy significativas. Si para trabajar 50 Has. eran necesarias 8.33 personas, sólo había que agregar 0.5 para trabajar hasta 200, es decir 150 Has. más. Una relación pare-

\footnotetext{
${ }^{39}$ DE PAULA y GUTIÉRREZ (1969)

${ }^{40}$ AGN Sala X 25-2-4 y 25-6-2.

41 TORASSA. (1940); DE PAULA y GUTIERREZ (1969); DE PAULA, GUTIERREZ y VIÑUALES (1974). ${ }^{42}$ SCHMIT (1999).

${ }^{43}$ Los cuadros de habitantes surgen de la comparación del Padrón de estancias con los censos de 1836 y 1838 que, lamentablemente, no informan sobre la composición interna de cada UC.

${ }^{44}$ Consideramos que las parcelas de nuestro padrón son el equivalente de las denominadas unidades censales de los padrones de población de 1836 y 1838 . A su vez, las UC son consideradas como unidades de producción familiares a las cuales, en al medida de las posibilidades del jefe de familia, se ha agregado de mano de obra externa bajo distintas formas. Ver al respecto GARAVAGLIA (1999: 77ss).
} 
cida puede establecerse con las parcelas de hasta 500 Has.; una persona más para laborar 300 Has. de incremento, es decir de 200 a 500 Has. No pasaba lo mismo con los que superaban dicha cantidad; necesitaban algo menos de brazos. Arriba de 1000 Has. los casos no pueden generalizarse, ya que sólo encontramos tres. Teniendo en cuenta que las unidades censales estaban compuestas básicamente por familias nucleares, nos parece una conclusión interesante la observación que en sólo 50 Has. podía establecerse un grupo familiar y que tal vez hasta le alcanzaba para vivir. Pero también se probó que el campesino de la colonia trabajaba una parcela con su familia y complementaba su ingreso conchabándose en estancias, como ya fue vislumbrado para la Banda Oriental ${ }^{45}$.

Desde otro ángulo, observamos que el promedio de habitantes por parcela no era parejo en todo el partido y era escasa la relación entre tamaño promedio de parcela y cantidad de habitantes. Donde las UC eran más grandes, cuarteles 3 y 6 , consecuentemente tenían mayor cantidad de habitantes. Sin embargo, en el cuartel 2 el promedio de individuos era de los más altos, a pesar de que la media de tamaño era chica. $Y$ con el 4, debemos recordar que se trataba del pueblo y sus chacras, a pesar de tener una de las menores medidas de parcela, la media de habitantes era mayor de la esperada. Estas diferencias zonales están indicando la imposibilidad de generalizar dentro del partido. Ya veremos a qué conclusiones arribamos con estos datos.

Pero como vimos al describir la fuente, no todos los empadronados como contribuyentes eran propietarios. Sin embargo, el censista asignó a los no propietarios un tipo de explotación, estancia o chacra. Sobre la base de esa información construimos el cuadro 8 . Con estos datos, y dados los tamaños asignados, resulta fácil colegir que las chacras no podían ser otra cosa que establecimientos agrícolas. Pero no todas las chacras tenían el tamaño asignado a esas suertes, como vimos en el cuadro 2; el escriba señalaba en la fuente que un contribuyente poseía una, una y media, dos y hasta 20 suertes contiguas denominadas de tal manera. Además, como también consignaba la medida en varas, en muchos casos indicaba que se trataba de una chacra, pero su tamaño era muy superior a la medida estipulada. Como se percibe, los tamaños señalados en teoría nada tenían que ver con la realidad.

Para desmentir esa fácil deducción, el cuadro 9 nos muestra que había chacras con ganados y estancias que no lo tenían. Sin embargo, de acuerdo con esta distribución, es evidente que las suertes de estancia estaban dedicadas con preferencia a la ganadería. Debemos tener en cuenta, como lo menciona Gelman ${ }^{46}$ analizando esta misma fuente, que los poseedores de menos 
de cincuenta cabezas no estaban alcanzados por la contribución directa, pero de todos modos no podemos considerar ganadero a aquel propietario que estaba en esa condición. Estos pequeños propietarios seguramente debían combinar esa ganadería minúscula con la agricultura. De tal modo, nuestra hipótesis, tal vez obvia, es que en el caso de los establecimientos denominados chacras se hacía esa conjunción.

\section{Hacienda}

Veremos ahora cómo se repartían el ganado que, según el censo de hacendados de 1837, se hallaba en el partido. En primer lugar, vemos que de las 154 unidades censadas, la mitad (78) no tenían ningún ganado. La totalidad era la siguiente.

$\begin{array}{lr}\text { Vacunos } & 10.205 \text { cabezas } \\ \text { Ovinos } & 52.350 \text { cabezas } \\ \text { Equinos } & 3.050 \text { cabezas }\end{array}$

La primera sorpresa es la cantidad de ovejas para una fecha tan temprana como 1837. Es decir que si "hacia fines de la década de 1840 y en muchas zonas de la provincia el ovino gradualmente comenzaba a desplazar al vacuno del lugar de preeminencia" ${ }^{\prime 4}$, en realidad este proceso habría comenzado antes en Quilmes. Es necesario prestar atención a este hecho, ya que había cinco veces más ovejas que vacas, que por otra parte coincidiría con una aseveración de Garavaglia en el sentido de que el incremento de la producción lanar habría comenzado durante la década de 1830 pero se habría interrumpido abruptamente con el bloqueo de $1839^{48}$. Es probable que esto tenga que ver con el tipo y el tamaño de explotación que se realizaba en la zona. Sabemos, como ya vimos, que una suerte de estancia (1882 Has.) producía nada más que 90 cueros anuales, y como vimos, sólo dos unidades superaban ese tamaño. Asimismo, la oveja tenía, en la época de la "fiebre", requisitos menores en cuanto a tierra y mano de obra; 2000 ovejas necesitaban 500 Has. y eran atendidas por un hombre y su familia ${ }^{49}$. Y por último, habría que ver cómo se conciliaba la producción agrícola con esta abundancia de ovinos. En primer lugar, zonifiquemos esta realidad (cuadros 10 y 11).

Como para reafirmar las aseveraciones vertidas con anterioridad, en todos los cuarteles, salvo el 1, había más ovejas que vacas. Pero las proporciones eran muy diferentes en los que estaban más al sur, es decir más alejados de la ciudad de Buenos Aires. Evidentemente, los cuarteles 5 y 6 tenían más

\footnotetext{
47 SABATO (1989: 34).

48 GARAVAGLIA (1999).

49 SABATO (1989: 186).
} 
vocación ovejera que el resto del partido, ya que era mayor la cantidad absoluta de cabezas; eran más las UC con ganado bovino y el promedio de cabezas también era más alto. En cambio, en el 3 predominaba la ganadería vacuna, ya que el promedio por unidad duplicaba, triplicaba y hasta cuadruplicaba la cantidad de vacas por unidad de los otros cuarteles. El cuartel 2 era el que menos ganado por UC tenía, cosa lógica ya que predominaban las parcelas chicas. Sin embargo, el 4, en el que la mayoría de unidades pequeñas era aún mayor, el promedio de ganado vacuno por cada una era el segundo del partido. En el caso del cuartel 1 se pone en evidencia su orientación comercial, industrial (saladeros) y/o de servicios ${ }^{50}$. Esas 60 vacas estaban en una sola unidad, de la cual su titular no era el propietario de la tierra que ocupaba. Esta situación, propietario de ganado pero no de tierra, se daba en 28 casos, 8 en el cuartel 5. Este estado era común en la campaña desde fechas anteriores; varios testimonios hablan de agregados que eran propietarios de alguna "majadita" ${ }^{51}$, incluso en otros partidos.

Así como analizamos el grado de concentración de la tierra, hemos armado el cuadro 12 para revisar la propiedad de la hacienda. Hemos tomado como referencia para construir la escala correspondiente la equivalencia que propone Garavaglia ${ }^{52}$ en cuanto a la tasa de recepción del ganado vacuno, 2 Has. por cabeza, y de $0.5 \mathrm{Ha}$. para el ovino. Por tanto, los tramos de la misma se cuadruplican entre un tipo de hacienda y otro; por cada vaca contamos cuatro ovejas.

En el caso del ganado vacuno, nos encontramos que tan sólo el $6.3 \%$ de los propietarios concentraba más del $21 \%$ de las cabezas, aunque ninguno supera las 600 cabezas; pero hacia abajo existía una gran dispersión ya que el $60 \%$ de los dueños detentaban casi el $30 \%$ de las unidades. Sin embargo, un propietario de 500 vacas es considerado por Garavaglia como un pequeño pastor $^{53}$, que podía llegar a acumular si no vendía más del $10 \%$ de su stock cada año en el mercado citadino. Y los escalones intermedios -más de 50 y menos de 200 - que representaban el $49.2 \%$ poseían el $27.4 \%$ de los animales. Los tramos siguientes hacia arriba, menos de 500, eran poseedores de casi la mitad de todos los vacunos del partido. En cuanto al ovino, la cosa cambia fuertemente, ya que el primer escalón no existía; es decir el equivalente al propietario de ganado vacuno que tenía menos de 50 vacas, cuyo referente sería, con el parámetro mencionado, el que poseía menos de 200 ovejas. Es más, si tomamos los dos primeros escalones, con los vacunos sumamos $36 \%$ de

${ }^{50}$ Ver al respecto TORASSA (1940).

${ }^{51}$ MAYO (1995: 71ss).

52 GARAVAGLIA (1993a: 191) Nota 7.

${ }^{53}$ GARAVAGLIA (1999: 330, 331). 
los propietarios y $10 \%$ de las cabezas; con los ovinos tenemos sólo la mitad, tanto de los titulares, el $17 \%$, como del ganado, el $4.5 \%$. Si estas equivalencias son válidas, era menos difícil ser propietario de alguna vaca que de una majadita de ovejas. En la otra punta de la escala, el $8.5 \%$ de los propietarios tenían 11 puntos de porcentaje más de ovinos que sus pares, los dueños de bovinos, 32.5 a 21.6 . En un tramo intermedio, entre 400 y 800 ovejas, nos encontramos con el $44 \%$ de los propietarios y el $25 \%$ de las cabezas, que es la concentración más importante de dueños y la segunda en cabezas.

Como se ve, si bien la concentración en cuanto al ganado vacuno no era importante y en el ovino lo era en mayor proporción, existía cierta correlación entre ambos tipos de hacienda. Estas comprobaciones, al igual que las que venimos realizando en páginas anteriores, nos permiten deducir que la forma que asumía la cría de ovejas se diferenciaba claramente de la vacuna. Si tener alguna vaquita para tener leche y de vez en cuando vender alguna en el mercado era una forma de producción eminentemente más basada en el autoconsumo, la cría de ovejas parece estar más dirigida al mercado que a la autosatisfacción, a pesar de que el ovino estaba íntimamente ligado a la alimentación del paisano bonaerense.

Un dato de interés, que no es exactamente el objetivo del presente trabajo. Según el padrón de población de 1838, habitaban el partido 295 individuos considerados extranjeros, el $6.9 \%$ del total ${ }^{54}$, repartidos en 70 UC de las cuales en 32 casos los jefes de familia también eran extranjeros. No podemos saber cuál era su origen, aunque por sus apellidos la mayoría parece tener ascendencia anglosajona y muy pocos tenían ascendencia vasca o española. Hemos leído bastante acerca del desarrollo de la ganadería ovina apoyada en la inmigración de escoceses, irlandeses y vascos ${ }^{55}$. De los 59 propietarios de ovejas que se registraron en el padrón que nos ocupa, sólo cuatro titulares estaban censados como extranjeros, Kem, Young, Yates y Arrascaete, y sólo uno más, Faustino Ximenez de Paz, apellido de antigua presencia en la zona, contaba en su UC con 6 habitantes, sobre un total de 40, que se declaraban extranjeros. Estas cinco UC sumaban en total 21 no nativos. Lo que tratamos de demostrar es que esta ganadería ovina se está desarrollando sin la presencia y el empuje de las colectividades mencionadas que, según la historiografía, habrían sido las artífices de la fiebre del lanar.

\section{Relación entre tenencia de tierra y de ganado}

Para alimentar el ganado que figura en el padrón era necesario una

${ }^{54}$ SANTILLI (1997: 83).

s5 SABATO (1989); KOROL y SABATO (1981). 
cantidad de tierra que puede calcularse a partir de lo que los historiadores Ilaman tasa de recepción del ganado. Aunque ya hayamos hecho referencia a la misma, la cuestión amerita una explicación. Ésta es la relación existente entre la cantidad de ganado y la tierra necesaria para mantenerlo y reproducirlo y varía según el tipo de ganado. Por supuesto que también debe variar según la calidad de la tierra de que se ocupe. En el caso del entonces partido de Quilmes, el cuartel 3 era una tierra anegadiza y pantanosa, mientras que los cuarteles 5 y 6 estaban recortados por arroyos, riachos y lagunas que facilitaban las rinconadas y también el apacentamiento del ganado. Azcuy Ameghino y Martínez Dougnac realizan una operación que promedia tres zonas, Areco, Magdalena y Pilar, estableciendo que eran necesarias $1.72 \mathrm{Has}$. por cada cabeza vacuna, 1.2 por cada equina y 0.2 por cada ovina ${ }^{56}$. Debemos tener en cuenta que dicho cálculo se basa en el censo de hacendados de 1789 y nosotros pretendemos aplicar estos datos a 1837. Como ya dijimos, en el tiempo transcurrido, cincuenta años, se hicieron modificaciones en la tecnología como para poner entre paréntesis la validez de las conclusiones. Samuel Amaral se basa en equivalencias del censo provincial de 1881 para establecer una superficie de 3.4 Has. por unidad ganadera, que se corresponde con un vacuno, 0.8 equinos y 8 ovinos $^{57}$. Si la tasa de Azcuy puede pecar de antigua, en este caso nos estaríamos basando en relaciones de otros casi cincuenta años, pero posteriores. Además, se tomaría como base el promedio de toda la provincia de Buenos Aires, donde seguramente las aptitudes de las tierras no son las mismas que para la región que estamos analizando. Por último, Garavaglia fija un valor uniforme para toda la campaña de fines de la colonia y establece que por cada vaca, caballo o mula eran necesarias 2 Has., y por cada oveja 0.5 Has $^{58}$. Para este cálculo, el autor toma como modelo la estancia que él llama "típica" que medía 2500 Has. y que contemplaba, además del mantenimiento del ganado, una cantidad de tierra cultivada. Es decir que en las equivalencias de Garavaglia, se incluye también la agricultura. Dos Has. por cada vacuno quiere decir que una parte de esa tierra, además de alimentar a esa vaca, proporcionaba una cantidad dada de cereales y hortalizas.

Con estos datos, trataremos de establecer la relación existente entre la tenencia de tierra y de ganado y, para el caso de los sin tierra, cuánta necesitaban para la cantidad de ganado que poseían. Si tenemos en cuenta a todos los poseedores de ganado, sean o no propietarios de tierra, podemos establecer que, utilizando las relaciones proporcionadas por Amaral, la superficie ocupada asciende a 69908 Has. Si aplicamos la que propone Garavaglia, la canti-

\footnotetext{
${ }^{56}$ AZCUY AMEGHINO y MARTINEZ DOUGNAC (1989: 48).

${ }^{57}$ AMARAL y GHIO (1990: 634).

58 GARAVAGLIA (1993a)
} 
dad de tierra utilizada era de 52685 Has. Si hacemos lo propio con la que nos proporciona Azcuy Ameghino, el área se reduce a 31683 Has. La extensión total aproximada del entonces partido de Quilmes rondaba las 72000 Has., con lo cual queda invalidada la equivalencia utilizando la regla de Amaral, ya que toda la tierra disponible estaría ocupada por ganado, hasta los pantanos de la costa de los actuales partidos de Berazategui y Villa Elisa. El cálculo sobre la proporción de Azcuy Ameghino parece más razonable ya que la tierra ocupada por el ganado no superaría el $45 \%$, quedando el resto para la agricultura. También la utilización de la correspondencia de Garavaglia parece creíble, teniendo en cuenta que esas relaciones incluyen la tierra dedicada al cultivo. En este sentido, las conclusiones a las que arribamos coinciden con otro trabajo sobre San Nicolás, que utilizó estas mismas equivalencias ${ }^{59}$.

Sin embargo, cuando analizamos la situación particular de cada propietario, vemos que de los 48 propietarios de tierra y ganado, a sólo 11 les alcanzaría la tierra para mantener las cabezas declaradas, en el caso de utilizar la regla de Garavaglia, mientras que si se usa la relación de Azcuy, la cantidad asciende a 18. Tomados en conjunto los 48 dueños mencionados, para el primero faltarían más de 13000 Has. y para el segundo 4700 . En consecuencia, no hay duda que los propietarios no declaraban toda la tierra que poseían. Es decir poseían tierras fuera del régimen de propiedad, bajo arrendamiento, ocupación legal o ilegal, etc. Otra opción es la de pensar que la tecnología había cambiado lo suficiente como para mejorar la productividad sobre la que se basaron los cálculos hechos por los dos autores mencionados. Esta posibilidad ha sido prevista por Garavaglia ${ }^{60}$ en un trabajo posterior, que comprueba variaciones temporales y regionales en la tasa de recepción, con una aceleración de la productividad entre $1816 / 29$, un retroceso muy serio en los partidos de antiguo asentamiento como el que nos ocupa, que coincide con la sequía de 1829/32, y una lenta recuperación en algunas regiones para el período que se inicia en 1836. Quilmes se incluiría en la regionalización que hace el autor en las estancias de cercanía, cuya tasa era para el primer período de una hectárea por vacuno y media por ovino, habiendo recuperado su nivel para el lapso 1836/52.

\section{Posesión y propiedad de la tierra}

Lo primero que observamos en estas exposiciones es que el $80 \%$ (523) de los jefes de unidades censales, registrados en los padrones de 1836 (620) y

${ }^{59}$ CANEDO (1995).

${ }^{60}$ GARAVAGLIA (1998) 
1838 (648), no era propietario de la tierra en la que vivía. ¿Cuál era entonces la relación que tenían estos individuos con esa parcela? No nos quedan muchas alternativas a la idea de que el arrendamiento de tierras estaba extendido en esa zona como en otras de la campaña ${ }^{61}$. Las fuentes que aquí tratamos no nos dicen nada explícitamente al respecto. Pero en el padrón de 1836 hay una sugestiva repetición de nombres de titulares de UC que, a su vez, en la mayoría de los casos están registrados en el censo de hacendados de 1837 . Este hecho llama la atención no sólo por sí mismo, sino porque además se trata en general de personajes muy conocidos para la historia de Quilmes e incluso de Buenos Aires. Faustino Ximenez era el mayor propietario del partido y sus ancestros habían dado el nombre al arroyo que hoy separa las ciudades de Quilmes y Berazategui. Mariano Cárdenas era el descendiente de uno de los primeros propietarios de la zona. Piñero es el nombre actual de un barrio de Avellaneda. Felipe Senillosa y Manuel Obligado son personajes conocidos en la historia de la provincia, en lo económico y en lo político. No sería extraño que estos individuos arrendaran sus tierras en el partido a pequeños productores agropecuarios. De los Santacoloma hay poco que agregar al trabajo de Socolow $^{62}$. Este linaje no aparece en el censo de 1815 y no figura en el de 1838, por lo que podemos suponer que la famosa casa de los Santacoloma, cuyas ruinas se pueden ver hoy en Bernal- que era la residencia temporaria en 1815 del rico comerciante domiciliado en la ciudad, en 1838 era explotada en arrendamiento por sus herederos. Se proporciona en el cuadro 13 una lista con los casos más notorios que mencionamos.

También podrían ser arrendadores los 25 propietarios que no figuraban en ninguno de los padrones de habitantes. Es decir, podemos presumir que arrendaban sus tierras a terceros. Nos encontramos con una parcela de 943 Has., otras dos de 251 y 225 Has., otra de 144 y el resto menores. Pero la mitad de ellos, incluyendo a los cuatro mencionados, eran titulares a su vez de ganado, lo que hace difícil verlos como propietarios que arrendaban toda su tierra. Se trataba seguramente de dueños de tierra que no vivían en las mismas pero que las explotaban en forma directa aunque podrían arrendar parte de las mismas. Por lo tanto, no podemos hablar aquí de grandes terratenientes absentistas, ni de latifundistas explotadores del campesinado, pero sí de propietarios medianos que alquilaban toda o parte de su parcela y que, en algunos casos, vivían en otro partido o en la propia ciudad de Buenos Aires. Bajo ningún punto de vista se puede considerar que un propietario de $1000 \mathrm{Has}$. era un latifundista; no lo es hoy día, menos en aquella época. Además, los contratos de arrendamientos que nos muestra Fradkin para San José de Flores en 1821

${ }^{61}$ Sobre arrendamiento ver los trabajos de FRADKIN (1995 y 1999), BIROCCO (1992) y CILIBERTO (1999).

${ }^{62}$ SOCOLOW (1991). 
eran sobre superficies muy pequeñas, como promedio, de 4 cuadras, aproximadamente 4 Has., y los había aún menores a una cuadra cuadrada ${ }^{63}$.

Otro ejemplo; en el testamento de Catalina Macías ${ }^{64}$, de 1862, la segunda propietaria del partido, declara que había arrendatarios que le debían parte de sus cánones. Al tiempo de la confección de su testamento, Catalina vivía en la ciudad en una casa que era de su propiedad y de su hermano Esteban, y su tierra, algo disminuida, era explotada por sus hijos, en ese tiempo ubicada en el partido de Barracas al Sur. Por supuesto, ésto no quiere decir que en la década de 1830 pasara lo mismo, al contrario, lo pone en duda, ya que en la lista que construimos más arriba no figura, es decir, su parcela fue considerada como una sola en 1836. En ese año, su UC tenía 40 habitantes y 44 en 1838, sobre un terreno de 1305 Has., declaraba la propiedad de 400 ovejas. En todo caso, estamos ante una explotación que combinaba la producción directa con el arrendamiento de parte de sus tierras.

Es indudable, a partir de estos ejemplos, que la relación con la tierra era lo suficientemente compleja como para que ningún modelo construido previamente se ajuste a esta realidad. Las fuentes que aquí estamos considerando nos informan parcialmente acerca de esa relación. Creemos que el estudio de los inventarios que figuran en los testamentos puede incorporar datos que permitan agregar luz a estas relaciones.

\section{Conclusiones}

En principio, podemos encontrar tres o cuatro zonas bastante bien definidas dentro del partido. El sur, cuarteles 5 y 6 , de vieja data pero de renovada economía, cuyos habitantes se dedicaban principalmente a la ganadería vacuna, pero que en el lapso analizado estaban cambiando su orientación hacia la cría de ovejas. Es en estos cuarteles donde encontramos las propiedades más grandes (ver cuadro 3) y la mayor cantidad de ovejas, tanto en forma absoluta (cuadro 10) como en promedio por cada unidad (cuadro 11). Una segunda zona sería la antigua reducción y sus aledaños, como la cañada de Gaete. Había 7 propietarios que tenían como promedio 225 vacas cada uno (cuadro 11), pero además, de los 78 propietarios de tierra pero no de ganado, la mayor cantidad, 25, habitaban ese cuartel. También, de las 104 parcelas definidas por el censista como chacras, 28 pertenecían a ese cuartel, (cuadro 4) el segundo valor absoluto del partido. También vimos que la cantidad de habitantes por UC era alta en relación con el tamaño promedio de las parcelas (cuadro 7). Nuestra hipótesis es que aquí nos encontramos con las actividades

${ }^{63}$ FRADKIN (1999: 24).

${ }^{64}$ AGN Sucesiones 6834-1862. 
clásicas del campesinado agrícola ganadero, pequeños productores que se dedicaban a la agricultura, en su gran mayoría, de los cuales algunos podían complementar esa actividad con una corta cantidad de ganado, sobre todo vacuno. Una tercera zona sería el actual centro de Lomas de Zamora, en la que sus UC nucleaban 10.17 personas cada una (cuadro 7), el segundo del partido, en unidades cuyo tamaño promedio era de 67 Has. Si a ésto le agregamos que, por definición del escriba, la mayor cantidad de chacras de todo el partido estaba en él (cuadro 4) y la cantidad de vacas por UC también era la menor del partido, podemos concluir que su actividad principal era la agrícola especialmente, con una organización que superaba el marco de la economía tradicional campesina. En Lomas se estableció, en 1821, el clan Grigera, fundando una colonia de pequeños productores agropecuarios. Estos serían los empresarios agrícolas de que nos habla Gelman ${ }^{65}$. Debemos observar, también, que en esta zona se incluía la ex colonia de escoceses de Santa Catalina y algunos otros propietarios importantes de ganado ovino. Por último, estaría el cuartel 1, lindante con el entonces Puente de la Restauración, del que ya hablamos bastante acerca de su actividad de servicios.

Pero aquí analizamos la situación de los que figuraban en el censo de propietarios. Veamos el cuadro 14. De las 648 UC registradas en el censo de 1838 , el $76.2 \%$ (entre el 70 y el $90 \%$ según el cuartel) no figuraba en el padrón de haciendas levantado un año antes, por lo tanto, los titulares de esas 494 UC no eran propietarios de tierra ni de ganado, o bien no alcanzaban el mínimo imponible, mil o dos mil pesos según fueran solteros o casados. ¿A qué se dedicaba toda esa gente, conjuntamente con el $12 \%$ que era propietario y no tenía ganado? Aún en el caso que, como lo afirmaban los historiadores regionales de la "nueva corriente," consideremos a las 110 UC de no propietarios y sin ganado del cuartel 1 como comerciantes, restaba el $73 \%$ de UC en condiciones de suponer que se dedicaban a la labranza de la tierra. Por supuesto, al inferir la actividad agrícola por la negativa de la ganadera, habría que tener en cuenta otras actividades que ya habíamos observado en el censo de $1815^{66}$, como cazador, hornero, abastecedor, pescador, marinero, etc. que no podemos siquiera estimar. Si nos atenemos a 1815 , todas estas profesiones juntas no superaban el $8 \%$. Es decir que, aunque exageremos esa incidencia al $15 \%$, nos quedaremos con más o menos la mitad de las UC en la actividad agrícola.

Pero todo este razonamiento no tiene por objeto sólo demostrar que la agricultura seguía siendo un medio de vida válido en la campaña de Buenos Aires de fines de la década de 1830 . Nuestro propósito es probar que, tal como sucedía durante la colonia ${ }^{67}$, los cultivos convivían con la cría del ganado. Y

${ }^{65}$ GELMAN (1996a).

${ }^{66}$ SANTILLI (1994).

${ }^{67}$ HALPERIN DONGHI (1992); GELMAN (1998). 
como podemos apreciar, el porcentaje de labradores así definidos no era diferente en cada uno de los cuarteles, aún en aquéllos que, como el 2 y 4 , distinguimos que eran los que estaban más ocupados por labradores, con mayor o menor grado de evolución hacia una explotación más racional y eficiente. $\mathrm{Si}$ nuestra hipótesis es válida parecería que el tan mentado fin de la agricultura colonial no quiere decir el fin de la agricultura en el Río de la Plata. Las condiciones de tal supervivencia seguramente no fueron las mismas, luchando contra la importación de harinas, el crecimiento de la ganadería ovina, etc. y haciendo movimientos corporativos ${ }^{68}$ para obtener de la administración rosista el proteccionismo que finalmente, aunque por poco tiempo, les proporcionó la ley de aduanas de 1835. Hasta tal punto persistía que, en las cercanías de Buenos Aires (San Isidro, Morón, Quilmes), podríamos suponer que desplazó a la ganadería a la frontera. Si nuestro razonamiento es correcto, la ruptura de la convivencia que mencionábamos con anterioridad se produjo en esta zona, pero a favor de la agricultura. De tal manera podríamos concluir que la "expansión de la frontera de Buenos Aires" se apoyó indudablemente en la homónima "expansión ganadera en la campaña de Buenos Aires" pero no sólo fue una demostración del poder adquirido por los hacendados, sino además un condicionamiento impuesto por las necesidades del mercado consumidor porteño y, tal vez, por esa acción corporativa de los labradores que abastecían dicho mercado.

\section{Resumen}

\section{Propiedad y producción en tiempos de Rosas: Quilmes 1837}

A través del análisis de fuentes primarias, un censo de sujetos alcanzados por la contribución directa y los datos que aportan los padrones de 1838, trataremos de investigar las actividades y las propiedades de la población de un partido de las cercanías de Buenos Aires, Quilmes, en una época en que las transformaciones que se estaban operando en la sociedad rural afectaban todos los niveles de su cotidianeidad. En primer lugar, analizamos el tamaño de la propiedad, diferenciando zonas dentro del mismo partido y comparando con otros partidos de la misma campaña. También relacionamos estos datos con la cantidad de habitantes por cada una de las propiedades. También se analiza la cantidad de ganado que encontramos registrados en el partido y su grado de concentración, como así también la relación existente entre la hacienda y la tierra. Por último, y con base en los datos obtenidos, hacemos especulaciones

\section{${ }^{68}$ PEREYRA (1964).}


en torno a las actividades de los habitantes del partido más grande de los cercanos a la ciudad, y su diferenciación según sea la zona que habiten.

\section{Palabras claves}

Buenos Aires - Campaña - Quilmes - Tierra - Producción - Cercanías

\section{Summary}

Property and production in Rosas Times: Quilmes 1837

Through the analysis of primary sources, a census of individuals affected by direct tax, and the data provided by 1838 electoral rolls, we will attempt to investigate the activities and properties of the population of Quilmes, a district nearby Buenos Aires; in times in which transformations within rural society affected all levels of daily life. Firstly, property sizes are analyzed, differentiating zones within the same district, and making comparisons with other districts of the same hinterland. We also relate these data with the amount of inhabitants in each property. Besides, we analyze the amount of cattle we find in the district and its degree of concentration, as well as the relationship existing between cattle and land. Finally, and based upon the data so obtained, we speculate about the activities of inhabitants of the biggest district near the city, and its differentiation according to the zone they dwell in.

\section{Key Words:}

Buenos Aires - Hinterland - Quilmes - Land - Production - Nearness

\section{Bibliografía}

AMARAL, Samuel y GHIO, J.M. (1990) "Diezmos y producción agraria. Buenos Aires, 1750-1800" en Revista de Historia Económica. VIII, 3, Madrid.

AZCUY AMEGHINO, Eduardo (1995) El latifundio y la gran propiedad colonial rioplatense. Buenos Aires, Fernando García Cambeiro.

AZCUY AMEGHINO, Eduardo y MARTINEZ DOUGNAC, Gabriela (1989) Tierra y ganado en la campaña de Buenos Aires según los Censos de Hacendados de 1789. Buenos Aires, IIHES.

BIROCCO, Carlos M. (1992) "Arrendamientos rurales en la primera mitad del siglo XVIII" en GRESORES, Gabriela y BIROCCO, Carlos M. Arrendamientos, desalojos y subordinación campesina. Buenos Aires, Fernando García Cambeiro. BROWN, Jonathan (1979) A Socio-economic history of Argentina, 1776-1860. Cambridge.

BURGIN, Miron (1975) Aspectos económicos del federalismo argentino. 
Buenos Aires, Solar. ( 1ra. edición 1946).

CANEDO, Mariana (1995) Los pastores de Los Arroyos. (Mimeo).

CANEDO, Mariana (2000) Propietarios, ocupantes y pobladores. San Nicolás de los Arroyos, 12600-1860. Mar del Plata, Universidad de Mar del Plata - GIHRR. CILIBERTO, Valeria (1999) "Los agricultores de Flores, 1815-1838. Labradores "ricos" y labradores "pobres" en torno a la ciudad", en: FRADKIN, Raúl O., CANEDO, Mariana y MATEO, José (1999) Tierra, población y relaciones sociales en la campaña bonaerense (siglos XVIII y XIX ). Mar del Plata, Universidad de Mar del Plata.

CUTOLO, Vicente O. (1971) Nuevo diccionario biográfico argentino. Buenos Aires, Elche.

DE PAULA, Alberto S. J. y GUTIÉRREZ, Ramón (1969) Lomas de Zamora. Desde el siglo XVI hasta la creación del partido, 1861. La Plata, Archivo Histórico de la Provincia de Buenos Aires.

DE PAULA, Alberto S. J., GUTIÉRREZ, Ramón y VIÑUALES, Graciela María (1974) Del pago del Riachuelo al partido de Lanús. La Plata, Archivo Histórico de la Provincia de Buenos Aires.

ESTEVEZ, Alfredo (1960) “La contribución directa 1821-1852", en: Separata de la Revista de Ciencias Económicas. Año XLVIII Serie IV $n^{\circ} 10$. Buenos Aires, Universidad de Buenos Aires, Facultad de Ciencias Económicas.

FERNS, H.S. (1984) Gran Bretaña y Argentina en el siglo XIX. Buenos Aires, Solar. (1ra. edición 1960).

FRADKIN, Raúl O. (1995a) "Labradores al instante, arrendatarios eventuales. El arriendo rural en Buenos Aires a fines de la época colonial" en BJERG, María Mónica y REGUERA, Andrea (comp.) Problemas de la historia agraria. Nuevos debates y perspectivas de investigación. Tandil, IEHS.

FRADKIN, Raúl (1999) "Las quintas y el arrendamiento den Buenos Aires (siglos XVIII y XIX)", en: FRADKIN, Raúl O., CANEDO, Mariana y MATEO, José (1999) Tierra, población y relaciones sociales en la campaña bonaerense (siglos XVIII y XIX) Mar del Plata, Universidad de Mar del Plata.

GARAVAGLIA, Juan Carlos (1993a) "Las 'estancias' en la campaña de Buenos Aires. Los medios de producción (1750-1850)”, en: FRADKIN, Raúl O.(comp.) La historia agraria del Río de la Plata colonial. Los establecimientos productivos (II) Buenos Aires, CEAL.

GARAVAGLIA, Juan Carlos (1993b) "Los Labradores de San Isidro (siglos XVIII - XIX)" Desarrollo Económico No 128 Vol. 32. Buenos Aires.

GARAVAGLIA, Juan Carlos (1998) "Intensidad de uso de la tierra y tasas de ocupación ganadera en la pradera pampeana (1816-1852), en: Quinto Sol. Revista de historia regional $\mathrm{N}^{\circ} 2$, Instituto de Historia Regional, Facultad de Ciencias Humanas, Universidad Nacional de La Pampa, Santa Rosa.

GARAVAGLIA, Juan Carlos (1999) La economía rural en la campaña de Buenos Aires vista a través de sus precios (1754-1852), (Mimeo).

GARAVAGLIA, Juan Carlos (2000) "Un siglo de estancias en la campaña de Buenos Aires: 1751/1853", en: Hispanic American Historical Review. 
GELMAN, Jorge (1996a) Crecimiento agrario y población en la campaña bonaerense durante la época de Rosas. Tres partidos del sur en 1839. Cuadernos del Instituto Ravignani, $N^{\circ} 10$. Instituto de Historia Argentina y Americana Dr. Emilio Ravignani, Facultad de Filosofia y Letras. Universidad de Buenos Aires. Buenos Aires.

GELMAN, Jorge (1996b) "Unos números sorprendentes. Cambio y continuidad en el mundo agrario bonaerense durante la primera mitad del siglo XIX", en: Anuario IEHS. $\mathrm{N}^{\circ} 11$ Tandil, Instituto de Estudios Histórico-sociales, Universidad Nacional del Centro.

GELMAN, Jorge (1998) Campesinos y estancieros. Una región del Río de la Plata a fines de la época colonial. Buenos Aires, Editorial Los libros del Riel. GULLOTTA, Víctor Gabriel (1994) San Francisco Solano: una historia para contar (1580-1993). Quilmes, El Monje Editor.

HALPERIN DONGHI, Tulio (1963) "La expansión ganadera en la campaña de Buenos Aires (1810-1852)", en: Desarrollo Económico. №3, Buenos Aires.

HALPERIN DONGHI, Tulio (1972) Argentina, de la independencia a la confederación rosista. Buenos Aires, Paidós.

HALPERIN DONGHI, Tulio (1975) "La expansión de la frontera de Buenos Aires (1810-1852)", en: GIMENEZ ZAPIOLA, Marcos (comp.) El régimen oligárquico. Materiales para el estudio de la realidad argentina (hasta 1930). Buenos Aires, Amorrortu.

HALPERIN DONGHI, Tulio (1992) "Clase terrateniente y poder político en Buenos Aires (1820-1930)", en: Cuadernos de Historia Regional, No 15, Universidad Nacional de Luján, Luján.

INFESTA, María Elena (1993) "La enfiteusis en Buenos Aires 1820-1850", en: BONAUDO, Marta y PUCCIARELLI, Alfredo R. (comp.) La problemática agraria. Nuevas aproximaciones.(i) Buenos Aires, CEAL.

INFESTA, María Elena (1994) "Propiedad rural en la frontera. Azul, 1839", en: AAVV Enrique M. Barba in memorian. Estudios de Historia. Buenos Aires, Academia Nacional de Historia.

KOROL, Juan Carlos y SABATO, Hilda (1981) ¿Cómo fue la inmigración irlandesa a la Argentina. Buenos Aires, Plus Ultra.

MASCIOLI, Alejandra (1999) "Población y mano de obra al sur del Salado. Dolores en la primera mitad del siglo XIX", en: FRADKIN, Raúl O., CANEDO, Mariana y MATEO, José (1999) Tierra, población y relaciones sociales en la campaña bonaerense (siglos XVIII y XIX), Mar del Plata, Universidad de Mar del Plata. MATEO, José (1993) "Población y producción en un ecosistema agrario de la de la frontera del Salado (1815-1869)", en: MANDRINI, R. y REGUERA, A. (comps.) Huellas de la tierra. Indios, agricultores y hacendados en la pampa bonaerense. Tandil, IEHS.

MAYO, Carlos (1995) Estancia y sociedad en la pampa 1740-1820. Buenos Aires, Biblos.

NICOLAU, J. C. (1988) La reforma económico-financiera de la provincia de Buenos Aires (1821-1825). Liberalismo y economía. Buenos Aires, Fundación 
Banco de la Provincia de Buenos Aires.

OTAMENDI, Luis E. (1968) Historia de la reducción 1666-1812. Quilmes, Serie Archivos y fuentes de información, II, Municipalidad de Quilmes, Secretaría de Gobierno y Cultura.

PALERMO, Miguel Angel y BOIXADOS, Roxana Edith (1991) "Transformaciones en una comunidad desnaturalizada: Los Quilmes, del valle calchaquí a Buenos Aires", en: Anuario IEHS Vol. 6. UniCEN, Tandil.

PEREYRA, Horacio J. (1964) "Proteccionismo y desarrollo agrícola, un documento de la época de Rosas", en: Trabajos y comunicaciones $N^{\circ} 12$, La Plata.

SABATO, Hilda (1989) Capitalismo y ganadería en Buenos Aires: La fiebre del lanar 1850-1890. Buenos Aires, Sudamericana.

SANTILLI, Daniel V. (1997) ¿Cambio o continuidad? Acerca de la estructura socioeconómica de Quilmes 1815-1840, Tesis de Licenciatura, UBA.

SANTILLI, Daniel Víctor (1994) Estructura socioeconómica de un partido de la provincia de Buenos Aires: Quilmes 1815. Ponencia presentada en las V Jornadas Interescuelas Departamentos de Historia. Montevideo, (Mimeo)

SANTILLI, Daniel Víctor (2000) "Población y relaciones en la inmediata campaña de la ciudad de Buenos Aires. Un estudio de caso: Quilmes 1815-1840", en: Anuario IEHS. $\mathrm{N}^{\circ} 15$. Tandil, Instituto de Estudios Histórico - Sociales, Universidad Nacional del Centro.

SCHMIT, Roberto (1999) "Fronteras rioplatenses: Ocupación del espacio y estructura socio-ocupacional en el oriente entrerriano (1820-1850)" en GELMAN, J., GARAVAGLIA, J.C. y ZEBERIO, Blanca, Expansión capitalista y transformaciones regionales Relaciones sociales y empresas agrarias en la Argentina del siglo XIX. Buenos Aires, Ed. La Colmena

SOCOLOW, Susan (1991) Los mercaderes del Buenos Aires virreinal: Familia y comercio Buenos Aires, Ed. de la Flor.

TORASSA, Antonio (1940) El partido de Avellaneda - 1580/1890. La Plata, Archivo Histórico de la Provincia de Buenos Aires. 
Cuadro 1 - Dis tribución de la tierra por tamaño

\begin{tabular}{lrrrrr} 
Has. & Unidades & $\%$ & Hectareas & $\%$ & Promedio \\
\hline $0-50$ & 69 & 55,2 & 1342 & 5,1 & 19,45 \\
$51-200$ & 31 & 24,8 & 3362 & 12,8 & 108,45 \\
$201-500$ & 11 & 8,8 & 3323 & 12,6 & 302,09 \\
$501-1000$ & 11 & 8,8 & 7575 & 28,8 & 688,64 \\
$1001-3000$ & 1 & 0,8 & 1305 & 5,0 & 1305,00 \\
$>3001$ & 2 & 1,6 & 9413 & 35,8 & 4706,50 \\
\hline Total & 125 & 100,0 & 26320 & 100,0 & 210,56 \\
\hline
\end{tabular}

Fuente: AGN X-25-4-6

Cuadro 2 Dis tribución de la tierra por tamaño y tipo de explotación

\begin{tabular}{llrrrrr}
\hline \multicolumn{2}{c}{ Has. Unidades } & \multicolumn{2}{c}{$\%$ Hectareas } & $\%$ Promedio \\
\hline $0-50$ & Chacras & 65 & 69,1 & 1215 & 17,2 & 18,7 \\
& Estancias & 2 & 7,1 & 54 & 0,3 & 27,0 \\
\multirow{2}{*}{$51-200$} & Chacras & 22 & 23,4 & 2334 & 33,1 & 106,1 \\
& Estancias & 9 & 32,1 & 1028 & 5,6 & 114,2 \\
$201-500$ & Chacras & 4 & 4,3 & 1063 & 15,1 & 265,8 \\
& Estancias & 7 & 25,0 & 2260 & 12,4 & 322,9 \\
\multirow{5}{*}{$501-1000$} & Chacras & 2 & 2,1 & 1130 & 16,0 & 565,0 \\
& Estancias & 8 & 28,6 & 5505 & 30,1 & 688,1 \\
$1001-3000$ & Chacras & 1 & 1,1 & 1305 & 18,5 & 1305,0 \\
& Estancias & 0 & 0,0 & 0 & 0,0 & \\
$>3001$ & Chacras & 0 & 0,0 & 0 & 0,0 & \\
& Estancias & 2 & 7,1 & 9413 & 51,6 & 4706,5 \\
\hline \multirow{2}{*}{ Total } & Chacras & 94 & 100,0 & 7046 & 100,0 & 75,0 \\
& Estancias & 28 & 100,0 & 18259 & 100,0 & 652,1 \\
\hline
\end{tabular}

Fuente: AGN Sala X 25-2-4, 25-4-6 y 25-6-2

Cuadro 3 - Distribución de parcelas por tamaño y cuartel

\begin{tabular}{lrrrrrrrr} 
& \multicolumn{7}{c}{ Cuarteles } \\
\cline { 2 - 8 } Has. & 1 & 2 & 3 & 4 & 5 & 6 & S/D & Total \\
\hline $0-50$ & 10 & 15 & 6 & 23 & 2 & 2 & 11 & 69 \\
$51-200$ & 2 & 8 & 2 & 6 & 7 & 1 & 5 & 31 \\
$201-500$ & & 1 & 1 & & 4 & 3 & 2 & 11 \\
$501-1000$ & & 1 & 1 & & 4 & 4 & 1 & 11 \\
$1001-3000$ & & & 1 & & & & & 1 \\
$>3001$ & & & & & & 2 & & 2 \\
\hline Total & 12 & 25 & 11 & 29 & 17 & 12 & 19 & 125 \\
\hline
\end{tabular}

S/D: Contribuyentes no ubicados en ningún cuartel en los padrones de habitantes.

Fuente: AGN Sala X 25-2-4, 25-4-6 y 25-6-2

- Facultad de Ciencias Humanas - Universidad Nacional de La Pampa - 


\begin{tabular}{rrrrr}
\multicolumn{6}{c}{ Cuadro 4 - Clasificación de las suertes por cuartel } \\
\hline Cuartel & Chacras & Estancias & Sin datos & Total \\
\hline 1 & 13 & & & 13 \\
2 & 29 & 2 & 1 & 32 \\
3 & 8 & 2 & 1 & 11 \\
4 & 28 & 3 & 1 & 32 \\
5 & 7 & 18 & & 25 \\
6 & 1 & 15 & 1 & 17 \\
S/D & 18 & 5 & 1 & 24 \\
\hline Total & 104 & 45 & 5 & 154 \\
\hline
\end{tabular}

Fuente: AGN Sala X 25-2-4, 25-4-6 y 25-6-2

Cuadro 5 - Cantidad de habitantes dis tribuidas según tamaño de la parcela

\begin{tabular}{|c|c|c|c|c|c|c|c|}
\hline \multicolumn{8}{|c|}{ Tamaño en Hectáreas } \\
\hline Habitantes & $0-50$ & $51-200$ & $201-500$ & $501-1000$ & $1001-3000$ & $>3000$ & Total \\
\hline 1 a 5 & 9 & 4 & & 3 & & & 16 \\
\hline 6 a 10 & 31 & 14 & 7 & 4 & & & 56 \\
\hline 11 a 15 & 12 & 4 & & 2 & & & 18 \\
\hline 16 a 20 & 1 & 2 & & 1 & & & 4 \\
\hline 21 a 25 & & & 1 & & & & 1 \\
\hline 26 a 30 & & & & & & & 0 \\
\hline$+\operatorname{de} 30$ & & & & & 1 & 1 & 2 \\
\hline Sin datos & 16 & 7 & 3 & 1 & & 1 & 28 \\
\hline & 69 & 31 & 11 & 11 & 1 & 2 & 125 \\
\hline
\end{tabular}

S/D: Contribuyentes no ubicados en ningún cuartel en los padrones de habitantes.

Fuente: AGN Sala X 25-2-4, 25-4-6 y 25-6-2

Cuadro 6 - Promedio de habitantes por tamaño de parcela

\begin{tabular}{lr} 
Has. & Promedio \\
\hline $0-50$ & 8,33 \\
$51-200$ & 8,83 \\
$201-500$ & 9,88 \\
$501-1000$ & 9,10 \\
$1001-3000$ & 44,00 \\
$>3001$ & 40,00 \\
\hline
\end{tabular}

Fuente: AGN Sala X 25-2-4, 25-4-6 y 25-6-2 
Cuadro 7 Promedio de tamaño y de habitantes por cuartel

\begin{tabular}{ccc}
\hline Cuartel & Tamaño en Has. & Habitantes \\
\hline 1 & 24 & 5,75 \\
2 & 67 & 10,17 \\
3 & 214 & 12,00 \\
4 & 37 & 8,50 \\
5 & 187 & 7,38 \\
6 & 191 & 10,47 \\
\hline
\end{tabular}

Fuente: AGN Sala X 25-2-4, 25-4-6 y 25-6-2

\begin{tabular}{|c|c|c|c|c|}
\hline Cuadr & Chasifical & $\begin{array}{l}\text { ion de las } \\
\text { Estancias }\end{array}$ & $\begin{array}{l}\text { Darcelas por } \mathrm{t} \\
\text { No definidos }\end{array}$ & Total \\
\hline Propietarios & 94 & 28 & 3 & 125 \\
\hline No propietarios & 10 & 17 & $\underline{2}$ & 29 \\
\hline Total & 104 & 45 & 5 & 154 \\
\hline
\end{tabular}

Fuente: AGN Sala X 25-4-7

Cuadro 9 - Clasificación de las suertes por tenencia de ganado

\begin{tabular}{|c|c|c|c|c|}
\hline \multicolumn{2}{|c|}{ Chacras } & Estancias & idos & Total \\
\hline Con ganado & 32 & 40 & 4 & 76 \\
\hline Sin ganado & 72 & 5 & 1 & 78 \\
\hline Total & 104 & $\overline{45}$ & 5 & 154 \\
\hline
\end{tabular}

Fuente: AGN Sala X 25-4-7

Cuadro 10 - Distribución del ganado por cuartel

\begin{tabular}{crrr} 
Cuartel & Vacas & Ovejas & Caballos \\
\hline 1 & 60 & & \\
2 & 960 & 7350 & 235 \\
3 & 1250 & 4200 & 250 \\
4 & 1575 & 1500 & 350 \\
5 & 2710 & 17900 & 815 \\
6 & 1725 & 14600 & 950 \\
S/D & 1925 & 6800 & 450 \\
\hline Total & 10205 & 52350 & 3050 \\
\hline
\end{tabular}

S/D: Contribuyentes no ubicados en ningún cuartel en los padrones de habitantes.

Fuente: AGN Sala X 25-2-4, 25-4-6. y 25-6-2 


\section{Cuadro 11 - Cantidad de UC con ganado por cuartel}

\begin{tabular}{crrrrrr} 
Cuartel & \multicolumn{2}{c}{ Vacas } & \multicolumn{2}{c}{ Ovejas } & \multicolumn{2}{r}{ Caballos } \\
\hline & \multicolumn{2}{c}{ UC Promedio } & \multicolumn{2}{c}{ UC Promedio } & UC Promedio \\
1 & 1 & 60 & & & & \\
2 & 9 & 107 & 12 & 613 & 5 & 47 \\
3 & 3 & 417 & 5 & 840 & 3 & 83 \\
4 & 7 & 225 & 2 & 750 & 4 & 88 \\
5 & 19 & 143 & 20 & 895 & 16 & 51 \\
6 & 14 & 123 & 14 & 1043 & 15 & 63 \\
S/D & 10 & 193 & 6 & 1133 & 5 & 90 \\
\hline Total & 63 & 162 & 59 & 887 & 48 & 64 \\
\hline
\end{tabular}

S/D: Contribuyentes no ubicados en ningún cuartel en los padrones de habitantes.

Fuente: AGN Sala X 25-2-4, 25-4-6 y 25-6-2

Cuadro 12 - Concentración de la propiedad del Ganado

\begin{tabular}{rrrrrr} 
Vacuno & Unidades & $\%$ & Cabezas & $\%$ & Promedio \\
\cline { 2 - 6 } menos de 50 & 9 & 14,3 & 215 & 2,1 & 24 \\
menos de 100 & 14 & 22,2 & 805 & 7,9 & 58 \\
menos de 200 & 17 & 27,0 & 1985 & 19,5 & 117 \\
menos de 300 & 11 & 17,5 & 2250 & 22,0 & 205 \\
menos de 500 & 8 & 12,7 & 2750 & 26,9 & 344 \\
500 o más & 4 & 6,3 & 2200 & 21,6 & 550 \\
\cline { 2 - 6 } Total & 63 & & 10205 & & 162 \\
\hline
\end{tabular}

\begin{tabular}{rrrrrr} 
Ovino & Unidades & $\%$ & Cabezas & \multicolumn{2}{r}{$\%$ Promedio } \\
\cline { 2 - 6 } menos de 200 & 0 & 0,0 & 0 & 0,0 & \\
menos de 400 & 10 & 16,9 & 2350 & 4,5 & 235 \\
menos de 800 & 26 & 44,1 & 13100 & 25,0 & 504 \\
enos de 1200 & 11 & 18,6 & 10000 & 19,1 & 909 \\
enos de 2000 & 7 & 11,9 & 9900 & 18,9 & 1414 \\
2000 ó más & 5 & 8,5 & 17000 & 32,5 & 3400 \\
\cline { 2 - 6 } Total & 59 & & 52350 & & 887 \\
\hline
\end{tabular}

Fuente: AGN Sala X 25-4-6 
Cuadro 13 - Quilmes 1836 - Algunos titulares de UC repetidos

\begin{tabular}{lrrrrr}
\hline & 1836 & \multicolumn{3}{r}{1838} & 1837 \\
\cline { 2 - 7 } & UC & Habitantes & UC & Habitantes Tierra (1) \\
\hline Paulino Ximenez & 7 & 36 & 1 & 5 & 174 \\
Manuel Pintos & 7 & 38 & 1 & 29 & $(2)$ \\
Faustino Ximenez & 6 & 34 & 1 & 40 & 9412 \\
Ana Santacoloma & 6 & 63 & $(2)$ & & $(2)$ \\
Antonio Tollo & 6 & 72 & $(2)$ & & $(2)$ \\
Mariano Cárdenas & 5 & 32 & $(2)$ & & $(2)$ \\
Manuel Obligado & 4 & 26 & 2 & 37 & $(2)$ \\
Antonio Fernandez & 3 & 25 & 1 & 12 & 145 \\
Inocencio Gonzalez & 3 & 21 & 1 & 16 & 32 \\
Felipe Senillosa & 3 & 25 & $(2)$ & & $(2)$ \\
Pascuala Ferreyra & 2 & 13 & 1 & 10 & 136 \\
Pedro Molina & 2 & 14 & 1 & 8 & 94 \\
Tristán Valdez & 2 & 26 & 1 & 17 & 130 \\
Felipe Piñero & 2 & 23 & 1 & 5 & $(2)$ \\
Gregorio Rincón & 2 & 18 & 1 & 10 & $(2)$ \\
\hline
\end{tabular}

(1) Medida en Has.

(2) No registrados

Fuente: AGN Sala X 25-2-4, 25-4-6 y 25-6-2

Cuadro 14 - UC no ubicadas en el "Padrón de haciendas..."

\begin{tabular}{rrrrr}
\hline Cuartel & $(1)$ & $(2)$ & Diferencia & $\%$ \\
\hline 1 & 122 & 13 & 109 & 89,3 \\
2 & 149 & 32 & 117 & 78,5 \\
3 & 41 & 11 & 30 & 73,2 \\
4 & 148 & 32 & 116 & 78,4 \\
5 & 126 & 25 & 101 & 80,2 \\
6 & 62 & 17 & 45 & 72,6 \\
s/d & & 24 & & \\
\cline { 3 - 5 } Total & 648 & 154 & 494 & 76,2 \\
\hline
\end{tabular}

(1) Padrón de 1838

(2) Padrón de haciendas 1837

Fuente: AGN Sala X 25-6-2, y 25-4-6 
Daniel V. Santilli

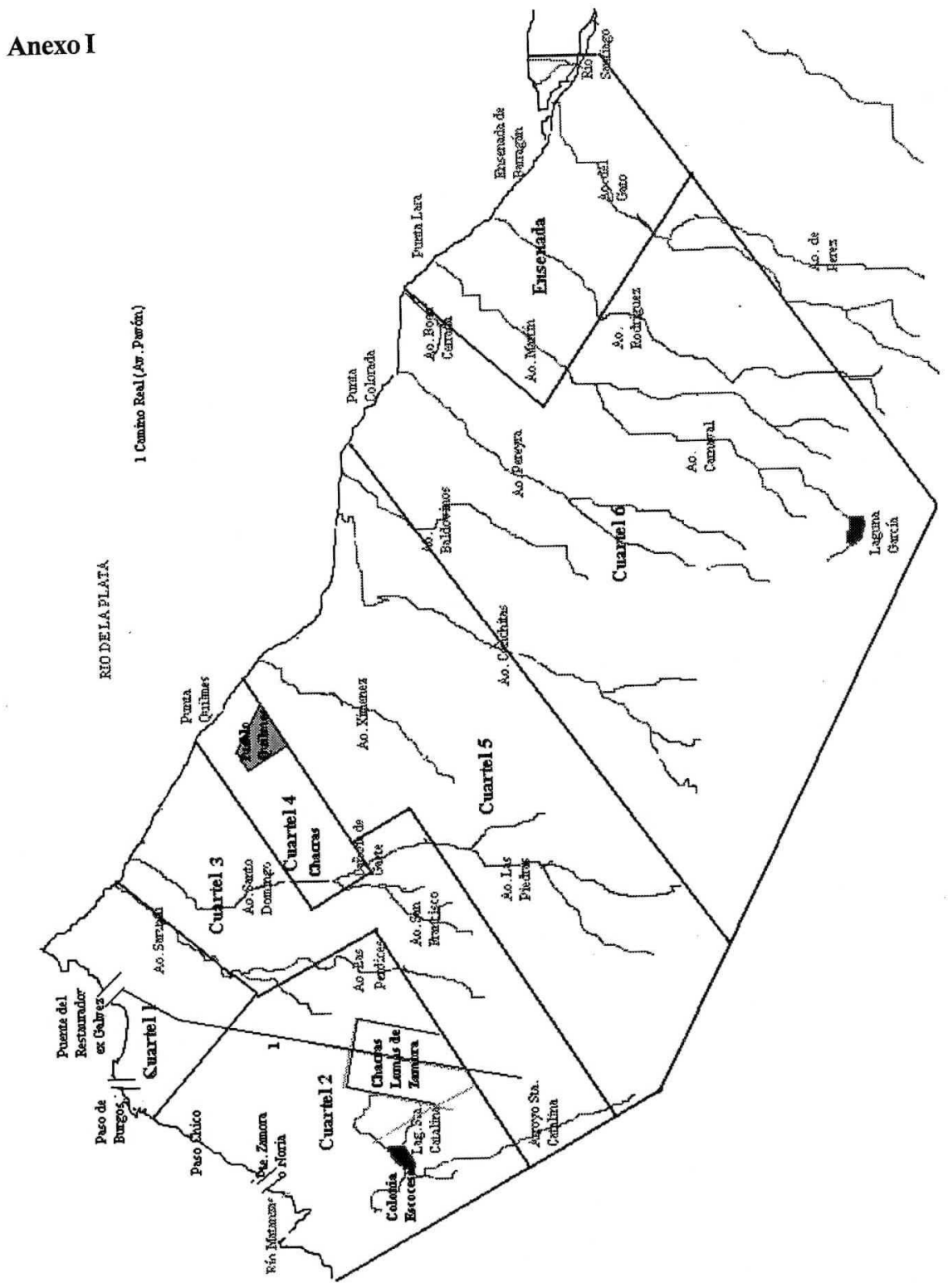

División por cuarteles del partido de Quilmes en 1836/38, según censos (AGN X-25-2-4 y X-25-6-2) 